\title{
Forming parameters optimizations with drawing force and die stress in wire rod drawing using rotating die under Coulomb friction
}

\author{
Ing-Kiat Tiong, Un-Chin Chai, and Gow-Yi Tzou* \\ Department of Mechanical and Automation Engineering, Chung Chou University of Science and \\ Technology, Changhua, 510, Taiwan
}

\begin{abstract}
An optimization research is performed on the related forming parameters of wire rod drawing through a rotating die under Coulomb friction. The optimization research is conducted through finite element method (FEM) simulation combined with Taguchi method. There are two drawing characteristic optimizations have been carried out. They are the optimizations with drawing force and die stress. The forming parameters considered in this study are half die angle, frictional coefficient, die fillet, and rotating angular velocity of the rotating die. The same procedure is carried out in both optimizations. The geometrical models of the wire rod, top die and rotating die are constructed firstly in SolidWorks and imported into the FEM simulation software named DEFORM 3D. With the aid of Taguchi method, the simulation experiments are carried out. The results such as drawing force, die stress, and the corresponding signal-to-noise $(\mathrm{S} / \mathrm{N})$ ratio are obtained and compared. The influence rank of the forming parameters and the optimal combination of parameters are obtained through the response table for both optimizations. The results such as effective stress, effective strain, velocity field, drawing force, and die stress are studied. The results show that the minimizations of drawing force and die stress are successfully achieved.
\end{abstract}

\section{Introduction}

Metal rod drawing is a well-known manufacturing process which applies a tensile force to stretch a metal rod into a desired cross-section or shape. This process is carried out at room temperature and it is considered as a cold working process. Sas-Boca et al. [1] carried out a FEM simulation on wire drawing process including the analysis of stress distribution and determined the optimum process parameters for the desired wire diameter. Chevalier [2] studied about the influence of geometrical parameters and friction on the quality of final wire through FEM simulation, and the result showed the friction ratio has no effect on the stress distribution, but it affects the global drawing force. Tang et al. [3] investigated the influence of drawing parameters on the forming of the micro copper tube with straight grooves and the results showed the reduction and die angle affect the drawing force while

*Corresponding author:gowyitzou@gm.ccut.edu.tw 
the die angle affects the stress in the multi-pass drawing process. Haddi et al. [4] performed a study on the relationship between drawing parameters and they developed a modified model to obtain the minimum drawing force and stress through the optimal combination of parameters obtained. El-Dominaty et al. [5] studied the thermal aspects of the wire-drawing process and the results obtained can be used for selecting the process parameters so that the minimization of temperature rise can be achieved. Kleinermann et al. [6] applied FEM simulation to solve a more complex problem named as inverse problem including parameters identification, initial geometry, and tool shape design. Wang et al. [7] successfully performed die design and modification by using advanced process simulation software and proved that it is better than old empirical method. Beland et al. [8] performed an optimization research on cold drawing process of 6063 aluminium tubes for reducing the drawing steps and drawing stress in the drawn tube. Tiernan et al. $[9,10]$ developed a machine for carrying out wire drawing without the use of conventional dies and they also presented a mathematical model of die-less drawing to represent the process of wire deformation. Walter et al. [11] performed process simulation on cold forming process and demonstrated die stress analysis on industrial problems. The results showed that the threedimensional simulation is very important for analyzing the die stress accurately. The reference mentioned above is related to the traditional drawing with a fixed die or without the use of a die. Tzou et al. [12] has demonstrated the FEM simulation using DEFORM 3D on rotating drawing with constant shear friction and they successfully explored the effect of forming parameters on the drawing characteristics. They also proved that the use of rotating die is able to reduce the drawing force and increase the material flow.

The aim of this study is to study the relationship between drawing characteristics and drawing parameters by performing the optimization research on the related forming parameters of metal rod drawing through a rotating die under Coulomb friction. In this study, the influence rank of forming parameters and the optimal combination of parameters are obtained.

\section{Pre-processing of drawing characteristics optimization}

Fig. 1 shows the schematic diagram of metal rod drawing with a front die and a rotating die. The material of the metal rod is set as SWRCH22AB. The flow rate of the metal rod is $\sigma=832.233 \varepsilon^{0.382} \mathrm{MPa}$ and this indicates that it is an elastic-plastic material. Coulomb friction is assumed along the interface between dies and work-piece. In this study, the metal rod is pulled by the top die with a fixed velocity, $\mathrm{V}_{0}$. As shown in Fig. $1, \mathrm{~V}_{0}$ is $33.5 \mathrm{~mm} / \mathrm{s}$ and the rotating die rotates with an angular velocity, $\omega(\mathrm{rad} / \mathrm{s})$ in an anticlockwise direction. The forming parameters related to drawing process are shown in Fig. 2; they are half die angle $\left(\alpha^{o}\right)$, frictional efficient $(\mu)$, die fillet $(\mathrm{R}, \mathrm{mm})$, and angular velocity of the rotating die $(\omega$, $\mathrm{rad} / \mathrm{s}$ ). Rigid-plastic FEM simulations are carried out through DEFORM 3D. With the aid of Taguchi method, the process of drawing characteristic optimizations is performed. The drawing parameters mentioned earlier are considered as the control factors for this study. Each control factor has three different levels. The overall simulation conditions are summarized in Table 1. 


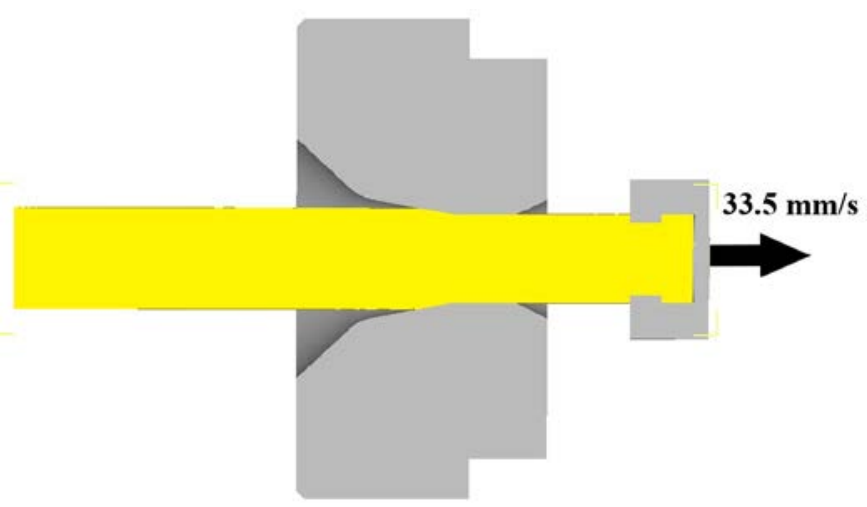

Fig. 1. Schematic diagram of metal rod drawing with rotating die and front die.

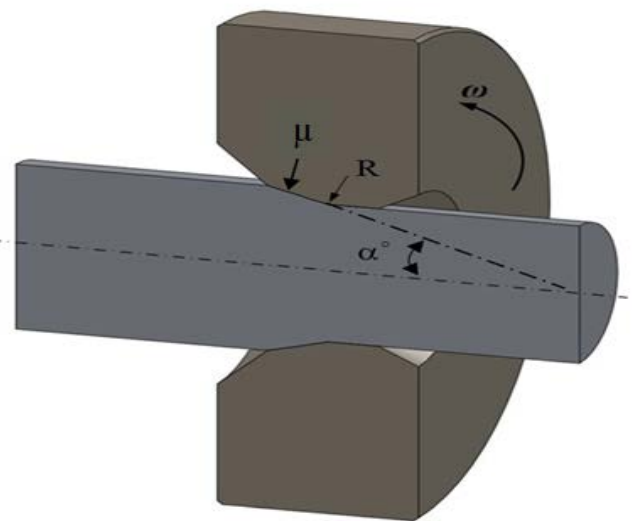

Fig. 2. Forming parameters of metal rod drawing.

Table 1. FEM simulation conditions.

\begin{tabular}{|l|c|}
\hline \multicolumn{2}{|c|}{ Metal Rod Conditions } \\
\hline Material & SWRCH22AB \\
\hline Object type & Plastic \\
\hline Young's Modulus, E [GPa] & 210 \\
\hline Poisson's Ratio, $v$ & 0.3 \\
\hline Power law [MPa] & $\sigma=832.233 \varepsilon^{0.382}$ \\
\hline Number of Elements & 60000 \\
\hline Diameter of Metal Rod, $\mathrm{D}_{0}[\mathrm{~mm}]$ & 6.4 \\
\hline Velocity of Metal Rod, $\mathrm{V}_{\mathrm{o}}[\mathrm{mm} / \mathrm{s}]$ & 33.5 \\
\hline Die Conditions & \\
\hline Diameter of Die, $\mathrm{D}_{\mathrm{d}}[\mathrm{mm}]$ & 5.6 \\
\hline Half Die Angle, $\alpha\left[{ }^{\circ}\right]$ & $10,14,18$ \\
\hline Frictional Coefficient, $\mu$ & $0.05,0.10,0.15$ \\
\hline Die Fillet, R [mm] & $3,5,7$ \\
\hline Rotating Angular Velocity, $\omega[\mathrm{rad} / \mathrm{s}]$ & $2.5,4.5,6.5$ \\
\hline
\end{tabular}




\section{Optimization analysis of drawing force}

The objective of performing drawing force optimization is to obtain the minimum drawing force in a rotating drawing process. Fig. 3 shows the fishbone diagram for drawing force optimization involving the control factors and levels mentioned in the previous part. Table 2 shows the $\mathrm{L}_{9}\left(3^{4}\right)$ orthogonal table for drawing force optimization. Referring to Table 2, nine sets of simulation experiments with different combinations of drawing parameters are carried out. The values of the parameters are determined by referring to the fishbone diagram in Fig. 3. FEM simulation experiments are performed through DEFORM $3 \mathrm{D}$. The corresponding drawing force and $\mathrm{S} / \mathrm{N}$ ratio for each experiment are obtained and summarized in Table 2. According to the results from Table 2, experiment 1 has the lowest value of drawing force $(4.33 \mathrm{kN})$ and the highest value of $\mathrm{S} / \mathrm{N}$ ratio $(-12.73)$, whereas experiment 9 has the largest value of drawing force $(6.35 \mathrm{kN})$ and the smallest value of $\mathrm{S} / \mathrm{N}$ ratio (-16.06). Since minimum drawing force is required, experiment 1 is determined as the best result for this study and experiment 9 is considered as the worst result. Table 3 is the response table of Taguchi method. Referring to Table 3, the frictional efficient $(\mu)$ has the highest influence on the drawing force following by half die angle $(\alpha)$, die fillet $(R)$ and angular velocity of the rotating die $(\omega)$. In Table 3, the level of each control factor with the highest value of $\mathrm{S} / \mathrm{N}$ ratio is selected and combined to form the optimal combination of parameters. The optimal combination of parameters is $\mathrm{A}_{1} \mathrm{~B}_{1} \mathrm{C}_{3} \mathrm{D}_{2}\left(\alpha=10^{\circ}, \mu=0.05, \mathrm{R}=7 \mathrm{~mm}\right.$, $\omega=4.5 \mathrm{rad} / \mathrm{s}$ ).

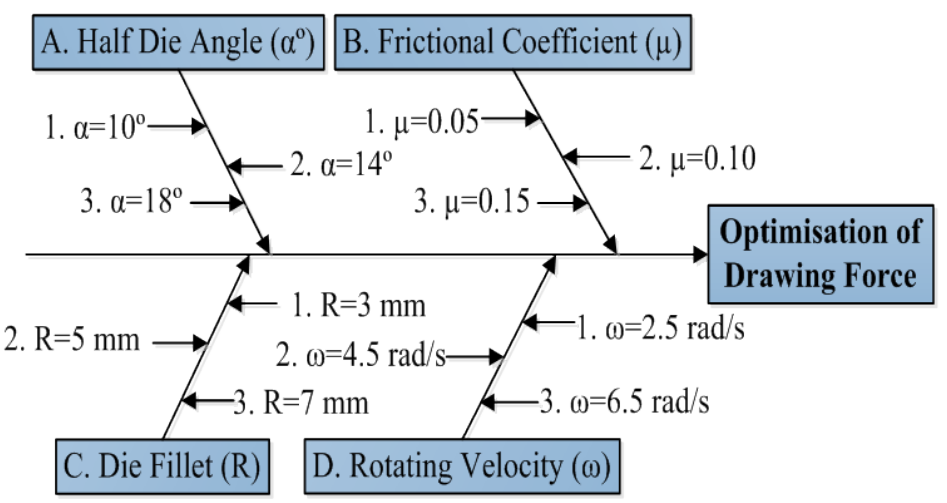

Fig. 3. Fishbone diagram for optimization of drawing force.

Table 2. $\mathrm{L}_{9}\left(3^{4}\right)$ orthogonal table for drawing force optimization and simulation results.

\begin{tabular}{|c|c|c|c|c|c|c|}
\hline Experiment & $\mathrm{A}(\alpha)$ & $\mathrm{B}(\mu)$ & $\mathrm{C}(\mathrm{R})$ & $\mathrm{D}(\omega)$ & Drawing Force $(\mathrm{kN})$ & $\mathrm{S} / \mathrm{N}$ Ratio \\
\hline 1 & 1 & 1 & 1 & 1 & 4.33091 & -12.73 \\
\hline 2 & 1 & 2 & 2 & 2 & 4.97430 & -13.93 \\
\hline 3 & 1 & 3 & 3 & 3 & 5.53731 & -14.87 \\
\hline 4 & 2 & 1 & 2 & 3 & 5.36975 & -14.60 \\
\hline 5 & 2 & 2 & 3 & 1 & 5.44790 & -14.72 \\
\hline 6 & 2 & 3 & 1 & 2 & 6.27132 & -15.95 \\
\hline 7 & 3 & 1 & 3 & 2 & 4.61509 & -13.28 \\
\hline 8 & 3 & 2 & 1 & 3 & 5.72152 & -15.15 \\
\hline 9 & 3 & 3 & 2 & 1 & 6.35088 & -16.06 \\
\hline
\end{tabular}


Table 3. Response table of $\mathrm{S} / \mathrm{N}$ ratio for drawing force optimization.

\begin{tabular}{|c|c|c|c|c|}
\hline S/N Ratio & $\mathrm{A}(\alpha)$ & $\mathrm{B}(\mu)$ & $\mathrm{C}(\mathrm{R})$ & $\mathrm{D}(\omega)$ \\
\hline Level 1 & -13.8441 & -13.5381 & -14.6097 & -14.5043 \\
\hline Level 2 & -15.0903 & -14.6031 & -14.8635 & -14.3885 \\
\hline Level 3 & -14.8302 & -15.6233 & -14.2914 & -14.8718 \\
\hline $\mathrm{E}(1->2)$ & -1.2462 & -1.0651 & -0.2538 & 0.1158 \\
\hline $\mathrm{E}(2->3)$ & 0.2601 & -1.0201 & 0.5721 & -0.4833 \\
\hline Effect & 1.25 & 2.09 & 0.57 & 0.48 \\
\hline Rank & 2 & 1 & 3 & 4 \\
\hline
\end{tabular}

Fig. 4 shows the diagram of effective stress, effective strain, and velocity field for experiment 9 which is the worst result. In Fig. 4, the maximum effective stress of experiment 9 is $734 \mathrm{MPa}$ and its maximum effective strain is $0.720 \mathrm{~mm} / \mathrm{mm}$. The velocity experienced by the metal rod is set to be the same value for all the experiment simulations. However, the range of the velocity field for each experiment simulation occurs to be slightly different. The range of velocity field for experiment 9 is between $23.7 \mathrm{~mm} / \mathrm{s}$ and $33.5 \mathrm{~mm} / \mathrm{s}$.
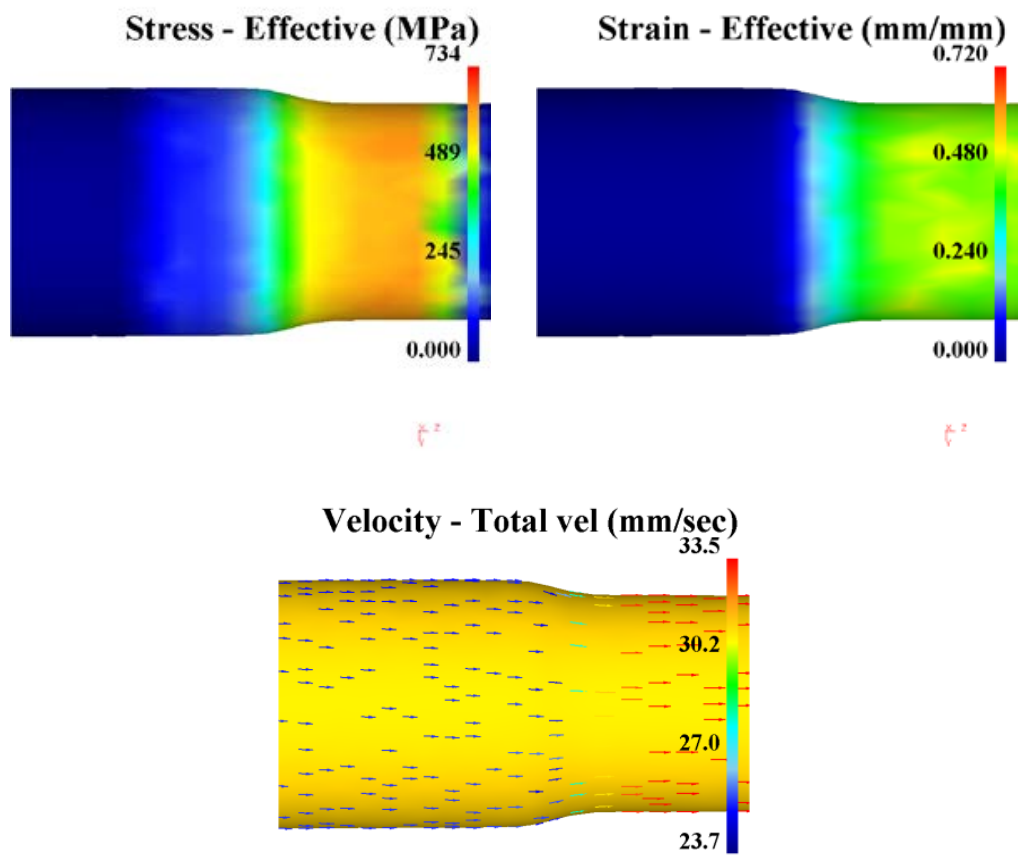

Fig. 4. Diagram of effective stress, effective strain, and velocity field for experiment 9 (worst result).

Fig. 5 shows the diagram of effective stress, effective strain, and velocity field for experiment 1 which is the best result. Referring to Fig. 5, the maximum effective stress for experiment 1 is $644 \mathrm{MPa}$ and its maximum effective strain is $0.511 \mathrm{~mm} / \mathrm{mm}$. Both of the maximum effective stress and strain for experiment 9 is higher than experiment 1 . The range of velocity field for experiment 1 is ranged from $25.4 \mathrm{~mm} / \mathrm{s}$ to $33.5 \mathrm{~mm} / \mathrm{s}$ which are overall higher than experiment 9. 

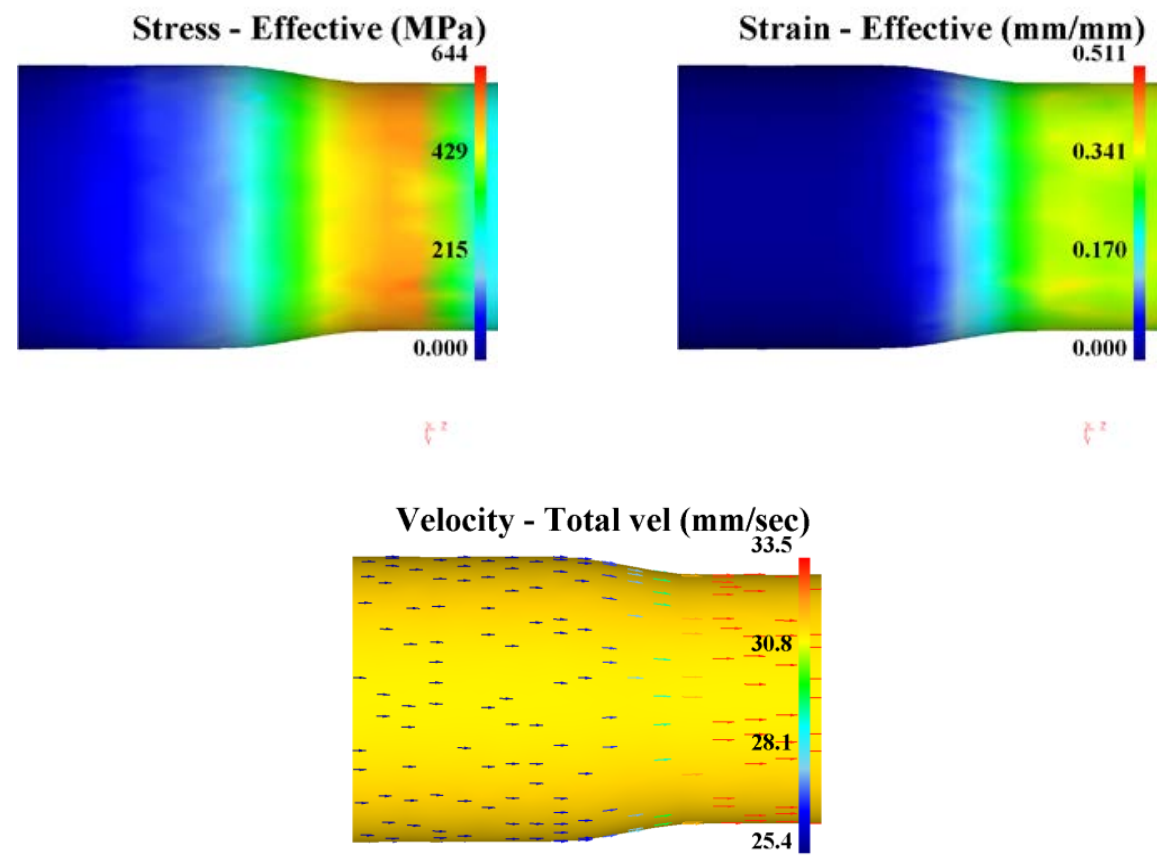

Fig. 5. Diagram of effective stress, effective strain, and velocity field for experiment 1 (best result).

Fig. 6 shows the diagram of effective stress, effective strain and velocity field for the optimal result $\left(\mathrm{A}_{1} \mathrm{~B}_{1} \mathrm{C}_{3} \mathrm{D}_{2}\right)$. According to Fig. 6, the maximum effective stress for the optimal result is $614 \mathrm{MPa}$ and its maximum effective strain is $0.452 \mathrm{~mm} / \mathrm{mm}$. The maximum effective stress and strain are lower than experiment 1 and 9.The range of velocity field for the optimal result is ranged from $25.5 \mathrm{~mm} / \mathrm{s}$ to $33.5 \mathrm{~mm} / \mathrm{s}$ which are higher than the best and worst simulation results. The minimization of metal rod drawing force is successfully carried out.
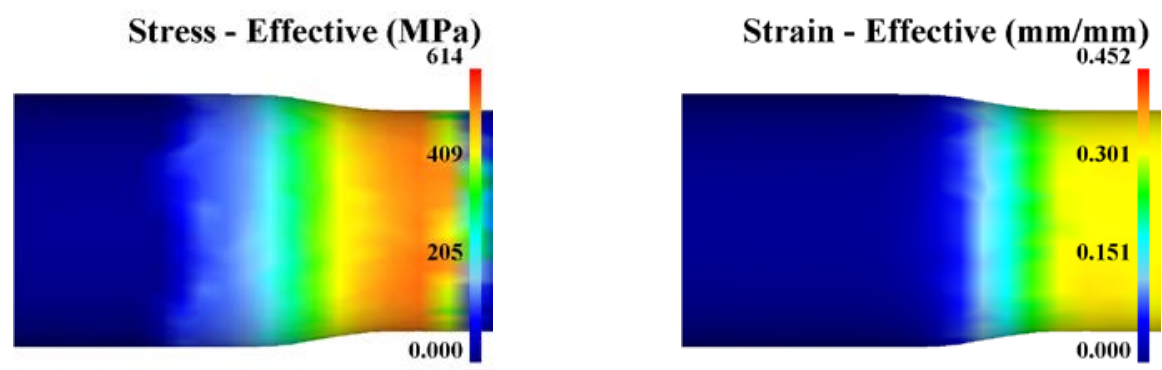


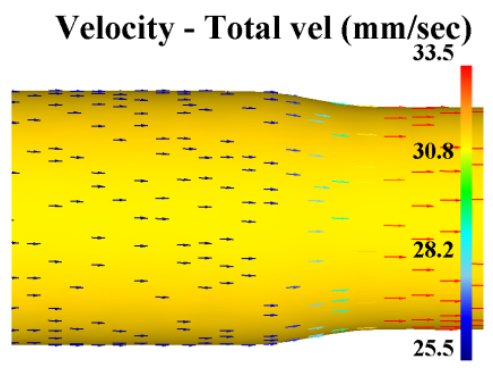

Fig. 6. Diagram of effective stress, effective strain, and velocity field for the optimal result.

\section{Optimization analysis of die stress}

Fig. 7 shows the fishbone diagram for the optimization of die stress involving the control factors and the corresponding levels. Table 4 shows the $\mathrm{L}_{9}\left(3^{4}\right)$ orthogonal table for die stress optimization. According to Table 4, there are nine simulation experiments with different combinations of parameters carried out for performing the die stress optimization. The combinations of parameters are similar for the optimizations of drawing force and die stress because the same orthogonal table is used for both optimizations. The value of levels for each control factors are chosen by referring to Fig. 7. FEM simulations are carried out by using DEFORM 3D. The die stress for each simulation experiment and its corresponding $\mathrm{S} / \mathrm{N}$ ratio are obtained and recorded in Table 4. From Table 4, the results show that experiment 3 has the lowest die stress $(770.94 \mathrm{MPa})$ and the highest value of $\mathrm{S} / \mathrm{N}$ ratio (-57.74) while experiment 1 has the largest die stress $(1330.77 \mathrm{MPa})$ and the smallest $\mathrm{S} / \mathrm{N}$ ratio (-62.38). The optimization of die stress aims to minimize the die stress. Since the minimum die stress is required, experiment 9 with the lowest die stress is considered as the best result and experiment 8 is determined as the worst result. Table 5 is the response table for the optimization of die stress. In Table 5, the die fillet (R) has the most significant influence on the die stress following by half die angle $(\alpha)$, frictional efficient $(\mu)$, and angular velocity of the rotating die $(\omega)$. Referring to Table 5, the level of each control factor with the highest $\mathrm{S} / \mathrm{N}$ ratio is chosen and combined to form the optimal combination of parameters. The optimal combination of parameters is determined as $\mathrm{A}_{1} \mathrm{~B}_{3} \mathrm{C}_{3} \mathrm{D}_{2}\left(\alpha=10^{\circ}\right.$, $\mu=0.15, \mathrm{R}=7 \mathrm{~mm}, \omega=4.5 \mathrm{rad} / \mathrm{s}$ ).

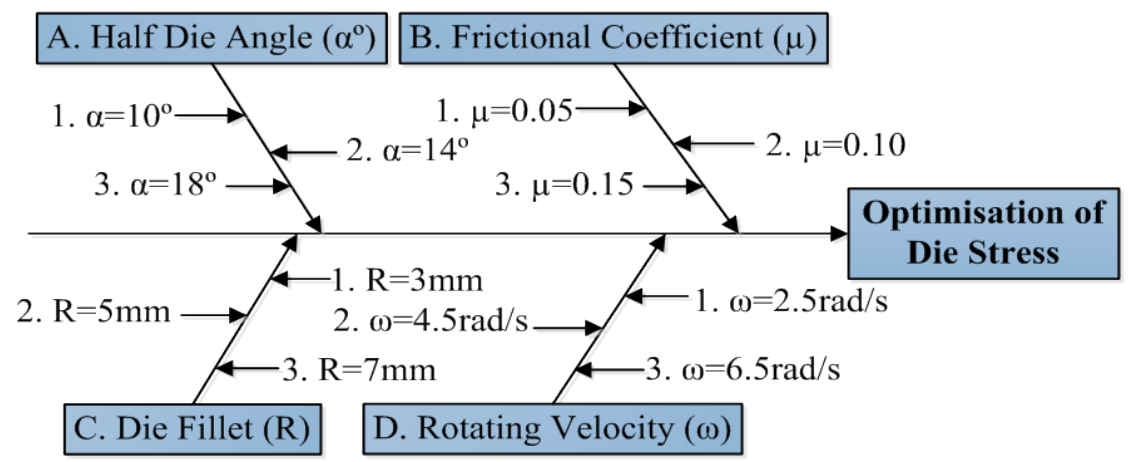

Fig. 7. Fishbone diagram for optimization of die stress. 
Table 4. $\mathrm{L}_{9}\left(3^{4}\right)$ orthogonal table for die stress optimization and simulation results.

\begin{tabular}{|c|c|c|c|c|c|c|}
\hline Experiment & $\mathrm{A}(\alpha)$ & $\mathrm{B}(\mu)$ & $\mathrm{C}(\mathrm{R})$ & $\mathrm{D}(\omega)$ & Die Stress $(\mathrm{MPa})$ & S/N Ratio \\
\hline 1 & 1 & 1 & 1 & 1 & 1099.00 & -60.82 \\
\hline 2 & 1 & 2 & 2 & 2 & 913.23 & -59.21 \\
\hline 3 & 1 & 3 & 3 & 3 & 770.94 & -57.74 \\
\hline 4 & 2 & 1 & 2 & 3 & 1061.46 & -60.52 \\
\hline 5 & 2 & 2 & 3 & 1 & 941.71 & -59.48 \\
\hline 6 & 2 & 3 & 1 & 2 & 1191.46 & -61.52 \\
\hline 7 & 3 & 1 & 3 & 2 & 904.09 & -59.12 \\
\hline 8 & 3 & 2 & 1 & 3 & 1330.77 & -62.48 \\
\hline 9 & 3 & 3 & 2 & 1 & 978.26 & -59.81 \\
\hline
\end{tabular}

Table 5. Response table of $\mathrm{S} / \mathrm{N}$ ratio for die stress optimization.

\begin{tabular}{|c|c|c|c|c|}
\hline S/N Ratio & $\mathrm{A}(\alpha)$ & $\mathrm{B}(\mu)$ & $\mathrm{C}(\mathrm{R})$ & $\mathrm{D}(\omega)$ \\
\hline Level 1 & -59.2573 & -60.1541 & -61.6079 & -60.0358 \\
\hline Level 2 & -60.5060 & -60.3907 & -59.8462 & -59.9525 \\
\hline Level 3 & -60.4718 & -59.6904 & -58.7810 & -60.2469 \\
\hline $\mathrm{E}(1->2)$ & -1.2487 & -0.2366 & 1.7616 & 0.0833 \\
\hline $\mathrm{E}(2->3)$ & 0.0342 & 0.7003 & 1.0652 & -0.2944 \\
\hline Effect & 1.25 & 0.70 & 2.83 & 0.29 \\
\hline Rank & 2 & 3 & 1 & 4 \\
\hline
\end{tabular}

Fig. 8 shows the diagram of die stress for experiment 8 which is the worst result of all the experiment simulations. Referring to Table 4, the average die stress of experiment 8 is 1330.77MPa.

\section{Die Stress (MPa) \\ 1640}

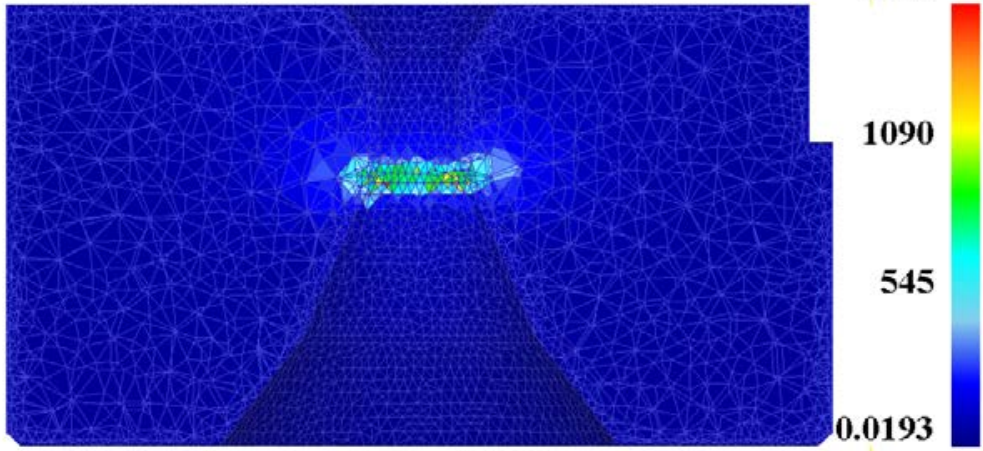

Fig. 8. Diagram of die stress for experiment 8 (worst result). 
Fig. 9 shows the diagram of die stress for experiment 3 which is the best result among all the experiment simulations. According to Table 4, the average die stress of experiment 3 is $770.94 \mathrm{MPa}$ and it is lower than the die stress of experiment 8 .

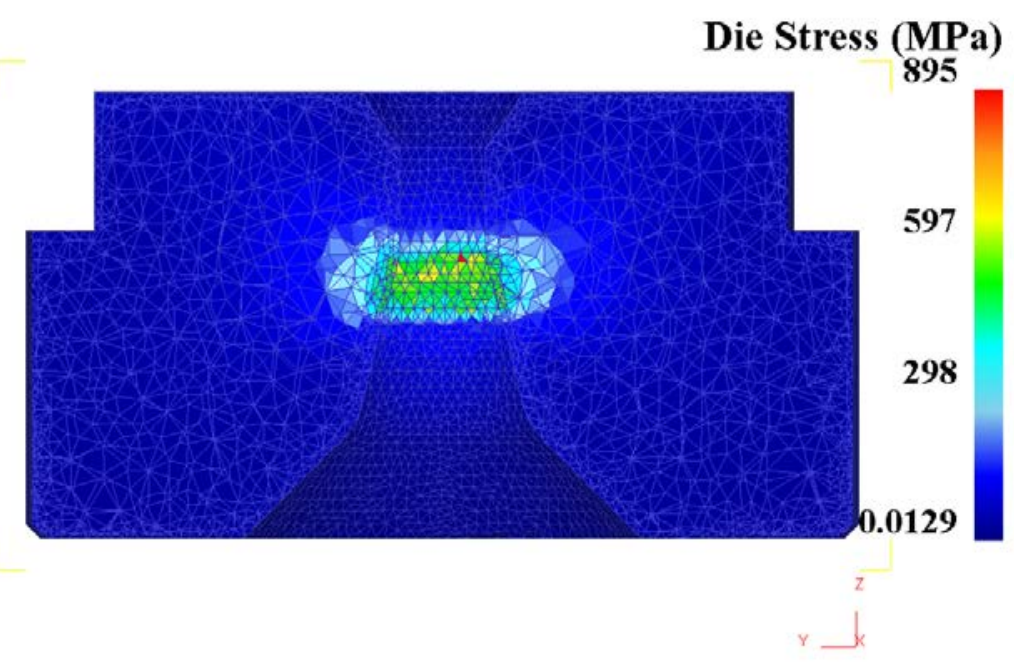

Fig. 9. Diagram of die stress for experiment 3 (best result).

Fig. 10 shows the diagram of die stress for the optimal result $\left(\mathrm{A}_{1} \mathrm{~B}_{3} \mathrm{C}_{3} \mathrm{D}_{2}\right)$. The average die stress for the optimal result is $750.89 \mathrm{MPa}$. The average die stress of the optimal result is lower than both of the best and worst simulation results. The minimization of die stress for metal rod drawing process is successfully performed.

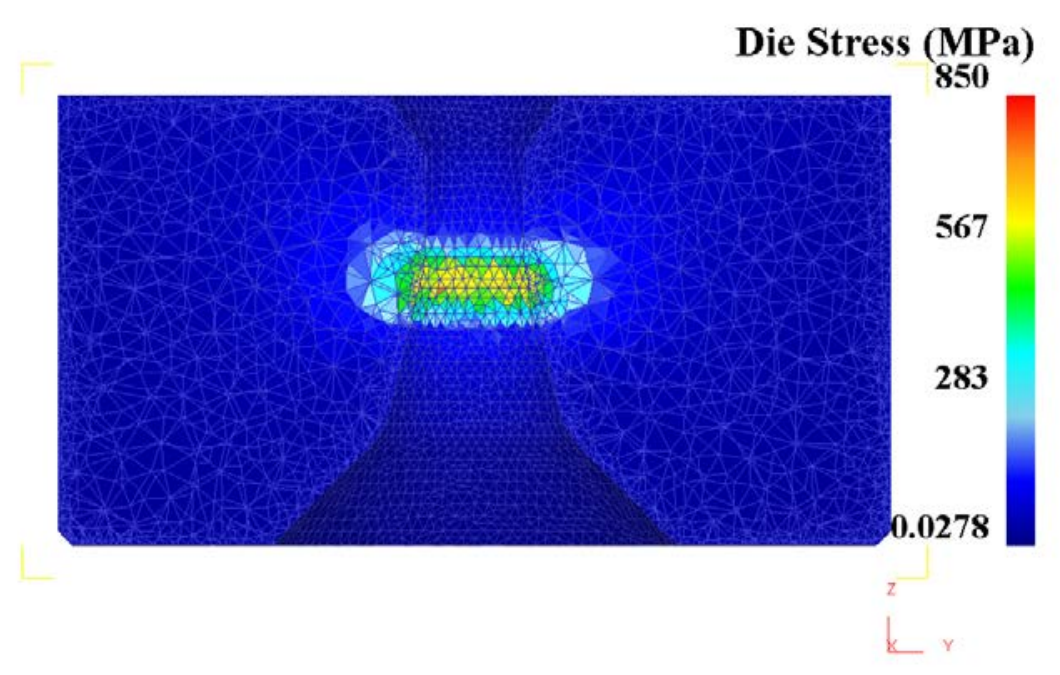

Fig. 10. Diagram of die stress for the optimal result. 


\section{Conclusions}

\subsection{Optimization of drawing force}

The objective of performing the optimization research on the drawing force for the metal rod drawing through FEM simulation and Taguchi method is to obtain the minimum drawing force. The influence rank of the drawing parameters to the drawing force is obtained through the response table of Taguchi method. The frictional coefficient $(\mu)$ has the largest influence to drawing force following by half die angle $(\alpha)$, die fillet $(R)$, and angular velocity of the rotating die $(\omega)$. The optimal combination of drawing parameters for drawing force optimization is $\mathrm{A}_{1} \mathrm{~B}_{1} \mathrm{C}_{3} \mathrm{D}_{2}\left(\alpha=10^{\circ}, \mu=0.05, \mathrm{R}=7 \mathrm{~mm}, \omega=4.5 \mathrm{rad} / \mathrm{s}\right)$. The drawing force, effective stress, effective strain, and velocity field for each experiment simulations are obtained and compared. Table 6 shows the improvement rate of the best and the worst results compared to the optimal result for the drawing force optimization. The drawing force of the optimal result is obtained to be $4.17 \mathrm{kN}$ which is smaller than the best $(4.33 \mathrm{kN})$ and the worst results $(6.35 \mathrm{kN})$. The drawing force is improved by $34.40 \%$ and $3.81 \%$ compared to the best and the worst results respectively. The improvement rate of the effective stress is in the range between $4.66 \%$ and $16.35 \%$ while the improvement rate of the effective strain is in the range between $11.55 \%$ and $37.22 \%$.

Table 6. Improvement rate (\%) of the best and worst results compared to the optimal result for the drawing force optimization.

\begin{tabular}{|c|c|c|c|c|c|}
\hline & $\begin{array}{c}\text { Best Result } \\
(\mathrm{BR})\end{array}$ & $\begin{array}{c}\text { Worst } \\
\text { Result (WR) }\end{array}$ & $\begin{array}{c}\text { Optimal } \\
\text { Result (OR) }\end{array}$ & $\begin{array}{c}\text { Improvement } \\
\text { (OR-BR)/BR }\end{array}$ & $\begin{array}{c}\text { Improvement } \\
\text { (OR-WR)/WR }\end{array}$ \\
\hline $\begin{array}{c}\text { Effective Stress } \\
(\mathrm{MPa})\end{array}$ & 644 & 734 & 614 & $4.66 \%$ & $16.35 \%$ \\
\hline $\begin{array}{c}\text { Effective Strain } \\
(\mathrm{mm} / \mathrm{mm})\end{array}$ & 0.511 & 0.720 & 0.452 & $11.55 \%$ & $37.22 \%$ \\
\hline $\begin{array}{c}\text { Drawing Force } \\
(\mathrm{kN})\end{array}$ & 4.33 & 6.35 & 4.17 & $3.81 \%$ & $34.40 \%$ \\
\hline
\end{tabular}

\subsection{Optimization of die stress}

The objective of performing the optimization research on the die stress for the metal rod drawing by applying FEM simulation and Taguchi method is to obtain the minimum die stress. The influence rank of the drawing parameters to the die stress is obtained through the response table. Die fillet $(\mathrm{R})$ has the highest influence on the die stress for metal rod drawing following by half die angle $(\alpha)$, frictional coefficient $(\mu)$ and angular velocity of the rotating die $(\omega)$. The optimal combination of drawing parameters for die stress optimization is $\mathrm{A}_{1} \mathrm{~B}_{3} \mathrm{C}_{3} \mathrm{D}_{2}\left(\alpha=10^{\circ}, \mu=0.15, \mathrm{R}=7 \mathrm{~mm}, \omega=4.5 \mathrm{rad} / \mathrm{s}\right)$. The die stress for each experiment simulations is summarized and compared. Table 7 shows the improvement rate of the best and the worst results compared to the optimal result for the die stress optimization. According to Table 7, the die stress is improved by $2.60 \%$ and $43.58 \%$ compared to the best and the worst results respectively. 
Table 7. Improvement rate (\%) of the best and worst results compared to the optimal result for the die stress optimization.

\begin{tabular}{|c|c|c|c|c|c|}
\hline & $\begin{array}{c}\text { Best Result } \\
(\mathrm{BR})\end{array}$ & $\begin{array}{c}\text { Worst } \\
\text { Result (WR) }\end{array}$ & $\begin{array}{c}\text { Optimum } \\
\text { Result (OR) }\end{array}$ & $\begin{array}{c}\text { Improvement } \\
\text { (OR-BR)/BR }\end{array}$ & $\begin{array}{c}\text { Improvement } \\
\text { (OR-WR)/WR }\end{array}$ \\
\hline Die Stress (MPa) & 770.94 & 1330.77 & 750.89 & $2.60 \%$ & $43.58 \%$ \\
\hline
\end{tabular}

Thanks for the financial support from Ministry of Science and Technology (MOST 104-2221-E-235002) to carry out this research successfully.

\section{References}

1. I.M. Sac-Boca, M. Tintelecan, M. Pop, D.A. Ilutiu-Varvara, A.M. Mihu, Pro. E. 181, 187-192 (2017)

2. L. Chevalier, J. Mat. P. Tech, 32, 145-153 (1992)

3. Y. Tang, D.S. Ou, Z.P. Wan, L.S. Lu, B. Lian, T. N. M. S. China, 21, 2264-2269 (2011)

4. A. Haddi, A. Imad, G. Vega, Mat. D, 32, 4310-4315 (2011)

5. A. El-Domiaty, S.Z. Kassab, J. Mat. P. Tach, 83, 72-83 (1998)

6. J.P. Kleinermann, J.P. Ponthot, J. Mat. P. Tech, 139, 521-526 (2003)

7. K.L. Wang, V. Argyropoulos, J. Mat. P. Tech, 166, 345-358 (2005)

8. J.F. Beland, M. Farard, A. Rahem, G, D’Amours, T. Cote, App. Math. M., 35, 53025313 (2011)

9. P. Tiernan, M.T. Hillery, J. Mat. P. Tech., 155-156, 1178-1183 (2004)

10. P. Tiernan, M.T. Hillery, J. Mat. P. Tech., 10, 12-20 (2008)

11. J. Walter, S. Kurtz, W.T. Wu, J. Tang, J. Mat. P. Tech., 71, 64-70 (1997)

12. G.Y. Tzou, D.C. Chen, S.H. Lin, Key. E. Mat, 716, 63-67 (2016) 